\title{
Fluorescence Spectra - An Effective method of Identification and Quantitative Assessment of Mixed Source Oils with varied thermal maturity
}

\author{
HANJING ZHANG ${ }^{1}$, SUMEI LI ${ }^{1 *}$ AND YONG CHEN ${ }^{2 *}$
}

${ }^{1}$ State Key Laboratory of Petroleum Resources and Prospecting, China University of Petroleum (Beijing), Beijing, 102249,

China (*Corresponding author, Email: smli@cup.edu.cn;)

${ }^{2}$ School of Geosciences, China University of Petroleum, Qingdao, Shandong, 266580, China (*Corresponding author, yongchenzy@upc.edu.cn)

This study is aimed to establish a fast and effective method using micro-fluorescence spectroscopy ${ }^{[1,2]}$ to identify and evaluate mixed source oils with varied thermal maturity in the Dongying Depression, Bohai Bay Basin. Two crude oils sourced from the fourth member of Eogene Shahejie Formation $\left(\mathrm{Es}_{4}\right)$ were selected as two end member oils for oil mixing experiment, which were featured by normal maturity (end member A from Well Wx583, reflected vitrinite reflectance $\mathrm{R} c=0.91 \%$ ) and less mature maturity (end member B from Well $\mathrm{Wx} 731, \mathrm{Rc}=0.53 \%$ ) respectively. The result indicates the artificially mixed oils showing an linear variation of fluorescence color in $\mathrm{CIE}-\mathrm{XY}^{[3]}$ (Commission internationale de l'eclairage) chromaticity diagram and apparently an intermediate features between the end member A and B. A negative relationship was observed between fluorescence spectral parameters QF-535 (The ratio of enveloping area between wavelengths 535 and $720 \mathrm{~nm}$ to that of the 420 and $535 \mathrm{~nm}$ ) and the mixing proportions of the two end members. A formula used for calculating the proportion of the mixed oil is as the follows:

$y=-224.06 x+411.59$ (The correlation coefficient $R^{2}$ is 0.87 ), in which, $\mathrm{X}$ is the fluorescence spectral parameter QF-535; $\mathrm{Y}$ is the proportion of the end member A mixed, representing the Es4 normal mature crude oil. Based on the formula combined with a comprehensive geochemical and geological investigation, we identified and quantitatively evaluated the mixed oils with different maturity in the Wangjiagan Oilfield in the Dongying Depression. For example, the matured Es4 origin oil from the Well W78 is about $92.5 \%$. This study is important for further petroleum exploration and resource assessment in the area.

[1] Radke $\mathrm{M}$ et al (1982). Geochimica Et Cosmochimica Acta, 46(1):1-10. [2] Khorasani G K (1987). Organic Geochemistry, 11(3):0-168. [3] Robertson A R (1977). Color Research \& Application, 2(1). 